\title{
A GLOBALIZAÇÃO E SUA INFLUÊNCIA NAS DECISÕES JUDICIAIS
}

\author{
Janine Taís Homem Echevarria Borba ${ }^{1}$ \\ Liana Zerbielli Trentin Mallmann²
}

\begin{abstract}
Resumo: A problemática do artigo é: A democracia sofre violação quando os juízes utilizamse de fundamentação nas suas sentenças decisões oriundas de outros países? Diante disso estruturou-se os objetivos específicos: Determinar a concepção contemporânea da ideia que se tem de transnacionalismo; Verificar como é percebido os fenômenos do "ativismo judicial" e da judicialização nas decisões judiciais brasileira; Apurar se a influência das decisões judiciais são violadoras de um sistema democrático. A metodologia foi a crítico- bibliográfica e o procedimento foi da pesquisa indireta em livros.
\end{abstract}

Palavras-chave: Transnacionalismo. Democracia. Ativismo Judicial. Comércio de juízes. Direito Global.

\section{GLOBALIZATION AND ITS INFLUENCE IN JUDICIAL DECISIONS}

\begin{abstract}
In order to achieve this objective and answer the problem is which is: Does democracy suffer violation when judges use jurisprudence from other countries in their decisions? Faced with this problem, they are specific objectives: To determine the contemporary conception of the idea of transnationalism; To verify how the phenomena of "judicial activism" and judicialization are perceived in Brazilian judicial decisions; Determine whether the influence of judicial decisions violate a democratic system. The methodology used was the critic-bibliographical and the procedure employed was the indirect research through books.
\end{abstract}

Keywords: Transnationalism. Democracy. Judicial Activism. Trade of judges. Global Law.

\footnotetext{
${ }^{1}$ Graduada em Direito pela IMED. Pós-graduada em Psicomotricidade Relaciona pelo La Salle/Canoas. Pósgraduada em Psicopedagogia Clínica e Institucional pela FEEVALE/Novo Hamburgo. Mestranda em Direito, Democracia e Sustentabilidade - IMED. Pós-graduanda em Direito Constitucional pela Faculdade Damásio. Pós-graduanda em Direito Civil e Processo Civil pela Faculdade IMED. Beneficiária de Bolsa PROSUP/CAPES vinculado ao Programa de Pós-Graduação Stricto Sensu em Direito - IMED. Integrante do Grupo de Estudo, Direitos Culturais e Pluralismo Jurídico. Advogada. Getúlio Vargas/RS. E-mail: janinehomemborba@gmail.com. Endereço para acessar este CV: http://lattes.cnpq.br/4368000701048089.

2 Mestranda do Programa Pós-graduação em Direito da Faculdade Meridional - IMED. Bolsista PROSUP/CAPES. Membro do Centro Brasileiro de Pesquisa sobre A Teoria da Justiça de Amartya Sen: interfaces com direito, políticas de desenvolvimento e democracia. Advogada. Lattes: http://lattes.cnpq.br/1577754433806541. E-mail: lianazerbielli@ hotmail.com.
}

Rev. de Argumentação e Hermeneutica Jurídica | e-ISSN: 2526-0103 | Porto Alegre | v. 4 | n. 2 | p. 80 - 101 | Jul/Dez. 2018 


\section{INTRODUÇÃO}

A globalização é um fenômeno que está presente no dia a dia de cada um dos cidadãos. Esse fenômeno oportunizou diversas mudanças estruturais nos Estados que abriram as portas para a comercialização de mercadorias ampliando dessa forma, as ofertas de produtos. $\mathrm{O}$ acesso a algumas tecnologias também contribuiu para que algumas pessoas tivessem alcance a telefones, celulares e internet, produtos que, anteriormente, eram acessíveis apenas para uma pequena parcela da população devido a onerosidade de tais produtos. Por óbvio a desigualdade que há entre as regiões, estados e países, é algo imensurável e, entende-se que a globalização também trouxe consigo alguns malefícios que fomentaram a desigualdade, esses também são desafios que a política transnacional precisa dar conta.

A globalização está ligada principalmente à economia, ao mercado econômico e ao comércio de produtos. Contudo esse artigo trata do papel que a globalização exerce no Poder Judiciário, isto é, como ela está, ou não, influenciando as decisões dos magistrados. Tem-se com isso que a permeabilidade das fronteiras entre os estados não foi somente no mercado econômico, mas outras áreas estão sendo inseridas, ou estão se inserindo nessa fusão, como é o caso do Poder Judiciário. Com a abertura das fronteiras dos estados percebe-se que se faz necessária uma transformação na sua estrutura, no entanto o que também deve ser levado em consideração é a Democracia, pois este é um instituo muito caro aos cidadãos dos países democráticos, por isso a sua violação deve ser abominada.

Frente a essas preocupações e, considerando a globalização como algo que não será exorcizado do nosso meio, é preciso refletir qual o alcance desse fenômeno no interior do estado. Na proposta desse trabalho, pretende-se considerar a sua influência no Poder Judiciário diante de um fato que se encontra no cotidiano dos tribunais que é o comércio entre juízes. O referido comércio é um recurso que os magistrados tem para formular suas decisões, ou seja, um magistrado brasileiro pode se valer de decisões estrangeiras para formar o seu convencimento e solucionar um conflito semelhante aqui no Brasil.

Dito isso, com o presente artigo buscar-se-á estabelecer as diretrizes pela qual vem passando as decisões judiciais pátrias frente ao transnacionalismo. A influência que este fenômeno possui nas decisões judicias é um fato cada vez mais presente no cotidiano do Poder Judiciário. Diante disso é fundamental que essa influência seja averiguada, com o

Rev. de Argumentação e Hermeneutica Jurídica | e-ISSN: 2526-0103 | Porto Alegre | v. 4 | n. 2 | p. 80 - 101 | Jul/Dez. 2018 
intuito de se compreender se a globalização pode chegar aos tribunais por meio da importação de decisões. O que se questiona é se a democracia sofre algum tipo de violação por parte dos juízes que utilizam-se de decisões estrangeiras para fundamentar as suas sentenças conforme foi decidido em outro país?

O objetivo geral desse artigo se resume em discutir sobre a influência do transnacionalismo nas decisões judiciais, bem como se essa influência pode ser uma violação à democracia. A partir de então traçou-se os objetivos específicos, quais sejam: 1) Determinar a concepção contemporânea da ideia que se tem de globalização, transnacionalismo, direito global; 2) Estabelecer uma definição, mesmo que provisória, do significado de comércio de juízes; 3) Verificar como é percebido os fenômenos do "ativismo judicial" e da judicialização nas decisões judiciais brasileira; 4) Apurar se a influência das decisões judiciais são violadoras de um sistema democrático. A metodologia utilizada para esta investigação foi a de uma abordagem crítico bibliográfica, com pesquisa em livros, artigos, periódicos, teses e jurisprudências.

\section{ESTRUTURAÇÃO HISTÓRICA DO ESTADO MODERNO, DA SOBERANIA E O ENFRAQUECIMENTO DAS FRONTEIRAS FRENTE À GLOBALIZAÇÃO}

Nesse capítulo tenciona-se estabelecer a relação entre o Estado e os fenômenos do transnacionalismo e da globalização. Sabe-se que a globalização é um fenômeno que desenrola-se no período do liberalismo diante de acontecimentos no mercado econômico. Ademais, a globalização também é compreendida como uma oposição ao Estado, de modo que esta instituição acaba tendo abalado um de seus pilares fundamentais que é a soberania, desafiando dessa forma a organização política econômica do país.

Inicialmente, os "Estados"3 gregos eram compreendidos até os limites das cidades, portanto uma cidade era considerado um "Estado". Os romanos, por sua vez, utilizavam a locução status reipublicae para descrever a ordem da coisa pública, que de certa feita também compreendia a existência de um "Estado". Subsequentemente, três instituições que formavam a população europeia, quais sejam: a nobreza, o clero e o povo, formavam naquele período o "Estado". Somente a partir do século XVI é que o vocábulo Estado vai paulatinamente se

\footnotetext{
${ }^{3} \mathrm{O}$ termo Estado só vai representar a estrutura conhecida atualmente, por meio de Maquiavel, que é o primeiro a usar a palavra Estado, portanto quando nos referimos a Estado (Grécia, Roma) ainda não é o vocábulo utilizado por aquela população, razão pela qual utilizamos aspas para identificar.
}

Rev. de Argumentação e Hermeneutica Jurídica | e-ISSN: 2526-0103 | Porto Alegre | v. 4 | n. 2 | p. 80 - 101 | Jul/Dez. 2018 
inserindo na organização política do ocidente. Preliminarmente, e provisoriamente, o Estado nasce da vontade do homem que desejava um bem que ultrapassasse o seu bem particular, mas que também pudesse garanti-lo e promovê-lo (AZAMBUJA, 1984, p. 2-7).

No entanto, conforme Morais (2010, p. 183) não há equívoco de que foi Maquiavel quem cunhou a palavra Estado: “Todos os Estados, todos os domínios que tiveram e têm império sobre os homens, foram e são ou repúblicas ou principados" (MAQUIAVEL, 1980?, p. 37). A compreensão dessa nova estrutura, qual seja, o Estado, parte do pressuposto de uma unidade de poder,

[...] a ideia de unidade é fundante do modelo de Estado que se estrutura com a passagem do medievo - como feudalismo, marcado por uma dispersão do poder político, bem como por uma disputa que se estabelece entre diversas instâncias de poder presente no medievo - rei, senhores feudais, igreja-, podendo-se caracterizar tal período pelo antônimo de unidade, ou seja, pluralismo de instâncias - para a era moderna. (MORAIS, 2010, p. 183)

Nessa nova organização se desenvolve o princípio da soberania. A soberania, nessa nova concepção, se caracteriza por centralizar todo o poder político, bem como pela produção e aplicação do direito. O Estado é o único capaz de dispor as condutas a serem observadas pelos moradores daquela localidade, outrossim, é somente por meio do Estado que há a possibilidade de punição quando um desses direitos for violado. A concepção originária, descrita pela filosofia política, entende que o Estado reúne os elementos formais e materiais, elencados como povo, território e governo, no entanto essa definição está sendo progressivamente rejeitada, pois o que importa efetivamente é a finalidade do Estado e não a sua composição (PINHEIRO FILHO; CHUT, 2009, p. 286).

A soberania contida no Estado, teve seu início com o Pacto de Paz de Westfália, em 1684, em outros termos, a noção de Estado soberano e centralizador, cujo papel é determinar em última esfera a ordem política e jurídica, portanto, é fruto do Pacto Westfaliano. Com efeito, o Estado Moderno não é uma evolução do Estado até então referido, pois não há um Estado antigo, mas o que ocorre são mudanças na concepção de Estado tendo como marco o advento da Revolução Francesa. "O liberalismo econômico que [...] veio a caracterizar o Estado até fins do século XIX, e daí a denominação, [...], de Estado liberal, constituiu um 
eufemismo enganador, a cuja sombra se processou rapidamente a hipertrofia do Estado moderno"” (AZAMBUJA, 1984, p. 145).

Conforme Morais (2010, p. 184) é relevante ainda, destacar que alguns autores como Bobbio, por exemplo, alertam que deve-se usar a terminologia Estado com cautela quando referirmo-nos às organizações anteriores à concentração e à centralização de poder em um território. Dito isso, os elementos que caracterizam o Estado moderno são a autonomia ou soberania plena do Estado e a distinção entre Estado e sociedade civil. No que se refere a primeira característica tal soberania não permite que o Estado dependa de outra autoridade, enquanto que a segunda característica reside no fato de que o Estado é uma organização separada da sociedade civil, em que pese seja a manifestação desta.

A primeira forma de Estado é chamada de Estado Estamental, pode-se considerar que esse Estado é uma transição entre a forma estatal do medievo e o Estado Absolutista, sendo esta última a primeira forma do Estado Moderno. O Estado Estamental era composto pela alta e baixa nobreza, do clero e da burguesia. Os pactos entre as classes eram regidos por lealdade e obediência aos príncipes e reis, esse pacto era elaborado com direitos e privilégios. Nessa organização o poder político de controle social encontrava-se nas mãos dos entes privados, assim como o poder econômico de modo que não se percebia nenhuma separação (MORAIS, 2010, p. 185).

O Estado Absolutista por sua vez é o primeiro modelo de Estado Moderno, ele surge “com base na figura do príncipe (monarca), um fenômeno de personalização e de centralização territorial do poder, em substituição ao modelo policêntrico e descentralizado que identificava o modelo medieval” (LEAL, 2009, p. 288-289). Nesse modelo, o Estado possuía o poder absoluto, pois não sofria limitações, não existia nenhuma autoridade além ou superior ao Estado, contudo essa prática levou a redução do potencial reflexivo do indivíduo. Esse centralismo e absolutismo leva a questionamentos e lutas internas, com o advento da revolução Francesa nascem ideais mais liberais sobre a política do Estado, cuja característica principal é o povo como detentor do poder em que a soberania do Estado era exercida por eles (TONET, 2013, p. 3-6).

\footnotetext{
${ }^{4}$ Para fins didáticos e poder estabelecer uma caracterização de cada período estatal vamos utilizar as duas nomenclaturas, isto é, utilizar-se-á Estado quando estivermos nos referindo as concepções anteriores a revolução Francesa, e a locução Estado moderno para os eventos após a referida revolução.
}

Rev. de Argumentação e Hermeneutica Jurídica | e-ISSN: 2526-0103 | Porto Alegre | v. 4 | n. 2 | p. 80 - 101 | Jul/Dez. 2018 
Esses ideais mais liberais formam o Estado Liberal cujo principal traço é a mínima intervenção estatal. A mediação na separação, anteriormente referida, entre o Estado e a sociedade civil é realizada pelo Direito.

\begin{abstract}
Assume como características a separação entre Estado e sociedade civil, mediada pelo direito, este visto como ideal de justiça; a garantia das liberdades individuais; os direitos do homem aparecendo como mediadores das relações entre os indivíduos e o Estado; a democracia surge vinculada ao ideário da soberania da nação produzida pela Revolução Francesa, implicando a aceitação da origem consensual do Estado, [...]; o Estado tem um papel mínimo, assegurando, assim, a liberdade de atuação dos indivíduos. (MORAIS, 2010, p. 187)
\end{abstract}

Essa liberdade de atuação dos indivíduos, decorre justamente da atuação negativa do Estado, que se submete à lei, há, por assim dizer, uma permuta na soberania do monarca (Estado Absolutista) pela soberania da lei, que obriga a todos (LEAL, 2009, p. 290). O Estado social, por sua vez, surge com o declínio da burguesia, momento em que o Estado se desprende desse domínio. O Estado social não perde as conquistas e valores impostos pelo liberalismo burguês, mas desenvolve um novo conteúdo político para superar as contradições e desigualdades que se evidenciaram no liberalismo. O estado social é um modelo paternalista e intervencionista, mas sem deixar de lado a liberdade (PINHEIRO FILHO; CHUT, 2009, p. 288).

O terceiro momento que caracteriza o Estado Moderno é o surgimento do Estado Democrático de Direito, que vai assumir um caráter de transformação que envolve tanto as conquistas democráticas, como as garantias jurídico-legais sem olvidar da preocupação social. O Estado Democrático de Direito tem o condão de transformação da realidade, estando inseridos nesse contexto questões como qualidade de vida individual e coletiva dos homens (LEAL, 2010, p. 188). Dito isso acerca da evolução histórica do Estado, tem-se um elemento que perpassa todos os modelos de Estado Moderno aqui descritos, qual seja a soberania.

A soberania tem sua origem no século XVI, momento em que há a "superação da descentralização feudal, como elemento integrador, harmonizador e garantidor da própria noção de Estado moderno" (ATZ; SUBTIL, 2010, p. 481). É possível, inicialmente, tecer um conceito provisório acerca da soberania, como um fenômeno alcançado a uma "pessoa ou instituição que exerce autoridade final dentro de um determinado território e sobre uma comunidade política específica" (ARGUELHES, 2009, p. 763). 
A soberania pode ser dividida em duas categorias distintas, uma chamada de interna e outra externa, no entanto essa diferenciação é realizada, mais para fins didáticos do que propriamente constitutivos, pois com o advento da globalização é difícil estabelecer balizamento entre os marcos políticos interno e externo (ATZ; SUBTIL, 2010, p. 483). Os autores seguem discorrendo sobre a soberania interna e externa, cuja compreensão de uma e de outra pode ser complementada pelo fato de que na soberania interna o soberano possui uma posição superior frente a soberania popular, enquanto que na soberania externa ele encontrase em condição de igualdade ante os demais soberanos. Nesse sentido,

a soberania interna representa o exercício da coerção estatal em um determinado
território, que é legitimado pela ordem pública. [...]. Historicamente, a soberania
nacional, portanto, resultara do processo de consolidação do Estado Moderno,
principalmente pela inclusão do sistema de representatividade política frente à antiga
ordem feudal de privilégios dos Estados e das organizações locais. [...]. A
politização da soberania externa fica clara frente à liberdade do soberano em decidir
sobre a paz ou sobre a guerra, pois não havia ordem jurídica superior para a
regulação de suas políticas externas. (ATZ; SUBTIL, 2010, p. 483)

E hoje como pode-se compreender o fenômeno da soberania? O conceito tradicional ainda se aplica? Para responder esses questionamentos deve-se começar pela segunda questão. Não, o conceito tradicional, o qual aqui denominamos provisório, não se pode aplicar de forma sagrada, pois adventos como a globalização permitiram a entrada de novos atores no cenário nacional, com isso as fronteiras foram se tornando cada vez mais tênues e, ao que parece não se tornarão mais robustas. Conforme Arguelhes (2009, p. 766) “o Estado parece ser incapaz de assegurar a unidade de sociedade cada vez mais plurais e fragmentadas, tornando-se apenas mais um ator importante dentre outros [...]”.

Nesse sentido, Habermas, quando da instalação do euro, em sua teoria apontava para questões como essa: "a vigência das fronteiras nacionais, a viabilidade da social democracia abarcar todos os países membros da região, portanto além das fronteiras nacionais, e as implicações do ponto de vista da legitimidade democrática frente a justiça social" (BARBOSA, 2011, p. 149). Habermas destaca essas questões justamente com o intuito, ao que nos aprece, de evidenciar a necessidade de se observar as diferenças sociais entre os Estados nacionais e para além disso como lidar com essas questões.

Bauman, por sua vez, compatibilizando, destaca que a globalização faz parte do cotidiano das pessoas, alguns a percebem como a razão para a felicidade enquanto que para 
outros é a mais pura infelicidade. Não obstante, a globalização é para todos "o destino irremediável do mundo, um processo irreversível; é também um processo que nos afeta a todos na mesma medida e da mesma maneira. Estamos todos sendo "globalizados" - e isso significa basicamente o mesmo para todos" (BAUMAN, 1999, n.p.). Habermas, a seu turno, entende que a globalização está ameaçando a organização do Estado social, ao seu ver a sobrevivência do Estado social e as suas atribuições só serão possíveis se os mesmos transporem de um "Estado nacional para organismos políticos que assumam de algum modo uma economia transnacionalizada", para o autor "uma economia globalizada foge às intervenções do Estado regulador” (HABERMAS, 2001 p. 69).

\begin{abstract}
Notadamente, os processos de globalização de maneira crescente criaram um mercado mundial, uma nova ordem supra e transnacional que permite a livre circulação de capitais, mercadorias, bens e serviços. Fez-se espaço para o exercício de um poder hegemônico de natureza técnica, econômica e financeira espraiado planetariamente, o qual demonstra a redução (crise) do Estado e institui instrumentos de governança global. (STAFFEN, 2015, p. 112)
\end{abstract}

Para além dos mercado mundial e da circulação de capitais, conforme o autor supra referiu, o transnacionalismo, advento esse proporcionado pelos processos de globalização, permeia por outras áreas, como por exemplo, nas decisões judiciais. No entanto antes de adentrar nesse conteúdo é preciso responder ao primeiro questionamento feito acerca da soberania. Atualmente o conceito de soberania é utilizado de modo mais maleável, o fenômeno foi relativizado para dar conta das necessidades dessa nova ordem. Nesse sentido a "globalização não pôs fim à soberania dos Estados, mas exigiu uma modificação nas suas estruturas e atuações" (WENTZ; STAFFEN, 2017, p. 174).

Essas modificações devem ser consideradas em outras áreas além do mercado econômico, pois a globalização vem ocupando espaços cada vez maiores, sendo um deles, o Poder Judiciário, órgão responsável em solucionar conflitos quando há violação de direitos. As decisões judiciais são o meio pelo qual é dada uma solução para as ações ajuizadas. Foram nessas decisões que se começou a perceber a influência das sentenças estrangeiras, por conseguinte, em um exercício dialético reflexivo começa-se a questionar se há possibilidade de se estar lançando mão de decisões estrangeiras para resolver casos concretos no país, ou se é mais um modo de ativismo judicial. 


\title{
3 MODELOS ESTRANGEIROS DE DECISÕES JUDICIAIS, COMÉRCIO DE
} JUÍZES 5

O fenômeno da globalização, que inicialmente, ocorreu por meio da circulação de capitais, do comércio e das grandes empresas, transformou o Estado nação, cujas fronteiras antes bem delimitadas, agora se encontram cada vez mais tênues. Essa nova caracterização gera a necessidade, por parte do Estado, de uma adequação no sistema político judiciário, uma vez que novos atores se juntam à nova estruturação promovida pela globalização. Nas palavras de Bauman, pode-se perceber a preocupação quanto a essa inserção de novos atores no Estado, pois não possuem um órgão diretor de quem emanam as condutas adequadas, ficando a cargo do próprio Estado a sujeição aos atores privados. Para o autor

\begin{abstract}
O significado mais profundo transmitido pela idéia da globalização é o do caráter indeterminado, indisciplinado e de autopropulsão dos assuntos mundiais; a ausência de um centro, de um painel de controle, de uma comissão diretora, de um gabinete administrativo. A globalização é a "nova desordem mundial” (BAUMAN, 1999, n.p.)
\end{abstract}

Diante da crítica exarada pelo autor, arrazoa-se como o Estado deve proceder frente a nova ordem mundial, por meio desse "cenário multivalente surgem diferentes transformações, conflitos e processos globalizatórios que contribuem para formação de um sistema de relações estatais especialmente distinto daquele antes concebido" (ZOLET; MORAIS, 2016, p. 448). Trata-se, portanto, de uma adequação constante a nova realidade reclamada pela globalização. A circulação de informações é algo premente o que torna todo o processo mais frenético e por isso demanda um cuidado redobrado em todas as áreas do conhecimento (WENTZ; STAFFEN, 2017, p. 174).

As modificações transpassam a área econômica e chegam ao Direito, "as estruturas jurídicas são, assim, forçadas a adaptar-se à interação econômica e à nova constituição social, e a colocar-se em coerência com elas" (ARNAUD, 2007, p. 67). Via de regra, todos os poderes do Estado sofrem mutações e precisam se adaptar a essa realidade transnacional gerada pela globalização, ao passo que o Poder Legislativo também carece de uma adequação.

\footnotetext{
${ }^{5}$ É importante destacar que esta palavra "juízes" ou "juiz" está sendo empregada de forma genérica, ou seja, ela pode estar se referindo a juízes de primeira instância, desembargadores e, inclusive, a Ministros dos tribunais superiores, bem como da esfera federal ou estadual.
}

Rev. de Argumentação e Hermeneutica Jurídica | e-ISSN: 2526-0103 | Porto Alegre | v. 4 | n. 2 | p. 80 - 101 | Jul/Dez. 2018 
[...] até mesmo o Poder Legislativo (e porque não dizer o direito) vem sofrendo mutações: o eixo de pressão e a fontes normativas vem sofrendo um alargamento, provocado tanto pela globalização jurídica quanto pelo transnacionalismo. O surgimento de novos instrumentos jurídicos, a partir de agentes transnacionais e que surtem efeitos diretos, tanto no Estado, quanto na população, nas organizações nãogovernamentais e nas corporações, fazem com que o processo legislativo tradicional fique muitas vezes, relegado a um segundo plano, cedendo espaço para as relações técnicas, setorizadas, negociais e arbitrais, antes comuns apenas em questões comerciais, mas hoje envolvendo até mesmo questões de direitos humanos e segurança internacional (WENTZ; STAFFEN, 2017, p. 174)

Nesse cenário convém ressaltar que o papel do judiciário também está em fomentar meios alternativos de resolução de conflitos tanto nacionais quanto internacionais como a mediação, arbitragem, conciliação, inclusive extrajudiciais, demonstrando assim mais eficiência em seu labor, além de "desafogar" as abarrotadas varas judiciais (CANDEAS, 2008, p. 161). Ademais, o Direito como fruto do Estado soberano, move-se cada vez mais ultrapassando as fronteiras, adentrando em outros Estados do mesmo modo soberanos, contribuindo, dessa forma, na elaboração de aplicação das leis em países estrangeiros (WENTZ; STAFFEN, 2017, p. 174).

Como podemos perceber a globalização ainda não está, por assim dizer, solidificada instrumentalmente, mas marca mudanças pontuais nessa nova ordem mundial. Nesse momento vale regatar a crítica de Bauman acerca de não haver elementos que pontuem de modo geral as condutas dos atores privados transnacionais.

o mundo não parece mais uma totalidade e, sim, um campo de forças dispersas e
díspares, que se reúnem em pontos difíceis de prever e ganham impulso sem que
ninguém saiba realmente como pará-las. Em poucas palavras: ninguém parece estar
no controle agora. Pior ainda - não está claro o que seria, nas circunstâncias atuais,
"ter o controle". Como antes, todas as iniciativas e ações de ordenação são locais e
orientadas para questões específicas; mas não há mais uma localidade com
arrogância bastante para falarem nome da humanidade como um todo ou para ser
ouvida e obedecida pela humanidade ao se pronunciar. Nem há uma questão única
que possa captar e teleguiar a totalidade dos assuntos mundiais e impor a
concordância global. (BAUMAN, 1999, n.p.)

Para solucionar esse impasse acerca da falta de um documento que "regule" as condutas transnacionais, foi desenvolvido teorias com intenção de organizar uma constituição única para diversos países, os quais abririam mão da sua autonomia. Foram três institutos que se destacaram: constitucionalismo transnacional; constitucionalismo global; transconstitucionalismo. Em breve síntese descrever-se-á cada um deles. 
a) Constitucionalismo Transnacional: decorre da tradução de transnational constitutionalism, Consiste na elaboração de uma só Constituição aplicável a vários países. Nesse caso cada um dos países abriria mão de sua autonomia e escolheria os seus representantes para fazer parte a Assembleia Legislativa Constitucional. Algumas características desse constitucionalismo é que ele ultrapassa as fronteiras do Estado; aplica-se tanto ao Estado como aos indivíduos; a alteração deve ser comum a todas as partes. Como exemplo pode-se citar o Tratado da União Europeia embora ainda inacabado (NUNES JÚNIOR, 2017, p. 92-94).

b) Constitucionalismo Global: é a tentativa de organizar um sistema normativo único de elementos materialmente constitucional. As características desse modelo são: alicerçamento do sistema jurídico-político ente o Estado e o povo; urgência em declarações e documentos internacionais legitimados em valores princípios e regras universais; ter a dignidade humana como um dos pilares do constitucionalismo. É um processo que vai aos poucos se consolidando, mas que é um meio capaz de combater a violação dos direitos humanos de países ditatoriais (NUNES JÚNIOR, 2017, p. 94-96).

c) Transconstitucionalismo: termo que foi forjado por Marcelo Neves, traduz-se em "um processo de convivência cooperativa entre as perspectivas jurídicas apresentadas por ordens jurídicas constitucionais e internacionais, um diálogo jurídico e cultural entre as várias instâncias decisórias" (NUNES JÚNIOR, 2017, p. 96). Diferentemente dos anteriores este modelo não pretende a unificação normativa regional ou mundial, mas busca a cooperação O Supremo Tribunal Federal vem paulatinamente utilizando tratados internacionais não incorporadas no ordenamento pátrio, assim como outras decisões estrangeiras. Ao que nos parece o transconstitucionalismo seria uma opção mais moderada para suprir essa lacuna (NUNES JÚNIOR, 2017, p. 96-97).

Por conseguinte, se faz necessário discorrer sobre o Direito Global para que depois possa-se inserir o comércio de juízes que é um consequência de todo processo globalizatório. O enfraquecimento do Estado nação e o avanço do Direito Global é promovido pela inserção de fatores de governanças nas políticas públicas dos Estados. O principal objetivo do Direito 
Global é justamente dar conta da demanda dos influxos e regular as relações proveniente da globalização (STAFFEN, 2018, p.16). Nesses termos, é conveniente sinalizar as diferenças conceituais entre o Direito Global e o Direito Internacional, pois não raras vezes há certa confusão no uso dessas locuções, assim,

O Direito Internacional resulta de acordos mútuos e recíprocos regidos pela soberania dos Estados e pela igualdade formal, o Direito Global, por seu turno, dispensa o papel central exercido pelos Estados. Além de facultar sua presença, quando partícipe, não lhe destina condições diferenciadas no trato das relações jurídicas. (STAFFEN, 2018, p.17)

Dessarte, o Brasil se considera um Estado Democrático de Direito, com o advento da Constituição Federal de 1988, que para a promoção do bem estar e do desenvolvimento, propriamente dito, deve ser planejada, organizada, bem como regulada por instrumentos legais, tendo como fim a real efetividade dos preceitos nela previsto. A efetividade dos ditames constitucionais, na maioria das vezes, obtém sua eficácia, por meio de normatizações realizadas pelo Poder Legislativo, pois é o órgão competente para tal. Não obstante, percebese que gradativamente o espaço legislativo vem sofrendo influências estrangeiras, ao passo que inclusive as fronteiras legislativas precisam de uma adequação para essa nova ordem mundial.

A adequação legislativa por vezes tarda, ocorrendo, por isso, a interferência judicial. Vislumbra-se que com o advento da emenda constitucional n. 45 , conhecida como a reforma do judiciário, o papel deste órgão se transformou, desde pelo aumento de demandas, como pelas decisões que são proferidas. O Poder Judiciário se tornou o ente que protege e promove os direitos fundamentais dos cidadãos, algumas vezes acertadamente e outras de forma a extrapolar a sua competência. Como não poderia deixar de ser, a globalização também começou a influenciar os juízes.

Há muito tempo não basta aos magistrados, sejam da instância que forem, apenas reproduzirem o que está na lei, como eram e ainda são, alguns positivistas críticos que ainda acreditam que o juiz seja a "boca da lei”. Ademais, a legislação brasileira impede que o juiz se utilize da expressão "non liquet”, ou seja, do juiz deve haver uma decisão para o caso posto. Para isso, nos casos em que a lei é omissa o magistrado pode utilizar-se de instrumentos como analogia, costumes e o famigerado princípios gerais do direito, 
Ou seja, o próprio juiz, neste processo de globalização, vale-se dos benefícios para solucionar possível omissão ou injustiça decorrente da lei nacional e soberana, e assim cumprir o seu papel na sociedade.

Este fenômeno, também chamado de "comércio entre juízes", se intensifica a partir do sentimento de proteção a um patrimônio democrático comum, bem como pela existência de silêncios normativos do direito positivo e da necessidade de uma maior regulamentação do mercado internacional, constituindo-se, desta forma, os juízes como agentes de primeiro plano na mundialização do direito. (WENTZ; STAFFEN, 2017, p. 176-177)

A partir da globalização pode-se inferir que são dois os recursos no qual o Poder Judiciário é capaz de encontrar auxílio para formar, tanto o seu convencimento, quanto para suprir eventuais lacunas no ordenamento jurídico. O primeiro é a importação legislativa e o segundo corresponde a jurisprudência estrangeira. A importação legislativa significa que o juiz pode se valer de normas do direito internacional, normas estrangeiras ou de organismos internacionais, ao passo que a jurisprudência estrangeira são consideradas todas as demais decisões proferidas no estrangeiro (WENTZ; STAFFEN, 2017, p. 177).

Um dos motivos que fomenta a inserção de novos recursos contributivos na formação do convencimento dos juízes é a crise que se instaurou nas tradicionais fontes do Direito. De outra banda, quando os tribunais recorrem ao uso de decisões estrangeiras estão contribuindo para interação judicial transnacional (STAFFEN, 2018, p. 32-33). O autor ainda refere os pressupostos, os quais considera indissociáveis, desse transjudicialismo: "manutenção e vinculação da rule of law; dever de motivação dos julgados; coerência das decisões e justificação das divergências (overruling e distinguishing) e; clareza e consistência nos argumentos" (STAFFEN, 2018, p.32).

A importação de legislação, aqui discutida, deve ser compreendida sob a ótica da proteção e promoção de direitos, em outros termos, busca-se na legislação externa normas capazes de solucionar os problemas exclusivamente internos. Cumpre destacar que esse "comércio entre juízes", contribui para o aprimoramento da justiça. A jurisprudência estrangeira, ao seu turno, promove aproximação com os juízes estrangeiros. É evidente que a utilização das decisões estrangeiras não podem ser a única para formar o juízo de convencimento do magistrado. Nos parece claro que o papel do intérprete ao empregar esse modelo jurídico deve ser o de contextualizar com o caso concreto e demonstrar a efetividade que tal decisão teve no estrangeiro (WENTZ; STAFFEN, 2017, p. 180). 
Os autores seguem ainda referindo que o uso de decisões estrangeiras pode ainda minimizar as diferenças entre os direitos humanos fundamentais, isto é

[...] pode o juiz, ao utilizar a jurisprudência estrangeira, também deixar de aplicar lei ou preceito nacional, visionando justamente a diminuição das diferenças entre as decisões nacionais e as decisões internacionais especialmente em materiais que envolvam direitos humanos fundamentais, de forma a tentar equiparar ao máximo esta sensível matéria em âmbito global, ou mesmo local, tendo em vista a existência de blocos associativos regionais. WENTZ; STAFEN, 2017, p. 180)

Assim sendo, e, frente “às mudanças ocasionadas pela globalização, [...], a tradição do Direito tem se visto obrigada a se adaptar aos novos paradigmas de uma governança global” (SERRAGLIO, 2015, p.157), saindo de um engessamento das normas nacionais. Porém, tal cenário nos faz refletir a respeito da legitimidade de ações que invistam nesses novos modelos, sem que haja a violação da democracia num país cujo ativismo judicial vem tomando proporções gigantescas.

\section{OS ASPECTOS RELEVANTES DO ATIVISMO JUDICIAL EM RELAÇÃO À INTERNALIZAÇÃO DAS DECISÕES ESTRANGEIRAS NO BRASIL}

A internalização das decisões estrangeiras no ordenamento jurídico pátrio, ocorre por meio de leis, sentenças entre outras decisões. É sob o viés democrático que se desenvolve o presente artigo, qual seja, a internalização mediante a aplicação de decisões estrangeiras nos conflitos exclusivamente nacionais, que não violem a legitimidade democrática é o tema a ser discutido. O emprego dessas decisões ocorre pela interpretação do juiz frente ao caso concreto, mas, antes de discorrermos sobre os aspectos de legitimação da internalização das decisões estrangeiras, é oportuno trazer ao debate questões como o ativismo judicial e a judicialização, fenômeno esse, presente corriqueiramente no exercer jurídico.

Inicialmente, parece-nos apropriado diferenciar o ativismo judicial da judicialização. Judicialização, nas palavras de Barroso (2013, p. 20) consiste na situação em que o Judiciário se transforma na última instância das decisões de largo alcance político, moral ou social, é uma consequência da disposição em que está organizado sistema brasileiro, cuja constitucionalização é ampla e os instrumentos de controle de constitucionalidade são abundantes. O ativismo judicial por sua vez, "é uma atitude: um modo proativo e expansivo 
de interpretar a Constituição, dela extraindo regras não expressamente criadas pelo constituinte ou pelo legislador" (BARROSO, 2013, p. 20).

Trata-se, portanto, de dois conceitos distintos, que em tese, não podem ser confundidos. A nosso ver, a judicialização é algo, em algumas circunstâncias, necessária para que os Direitos Fundamentais sejam alcançados aos cidadãos, um exemplo, são as demandas corriqueiras da área da saúde. O oposto da judicialização é o ativismo, cujo papel prepondera quando o magistrado extrapola a sua competência e passa a "legislar", ou seja, ocupando o lugar do Poder Legislativo. O ativismo judicial está intimamente ligado ao poder discricionário judicial, que para Hart (2011, P. 335), é uma faculdade do julgador quando se depara com lacunas na lei, podendo suprir essa omissão criando o direito para aquele caso concreto.

A discricionariedade assim como o ativismo judicial é comumente entendida a partir de uma postura negativa, ao passo que

[...] substituímos o juiz boca da lei pelo juiz que pondera princípios e que, portanto, decide conforme sua consciência, a partir de valorações de ordem subjetiva, passando, assim, de um mecanismo na aplicação do direito para um decisionismo [...] que vem reforçado pela ideia de que a discricionariedade é algo natural à decisão judicial.

[...] o ativismo judicial brasileiro, em cujas bases se encontram as ideias do neoconstitucionalismo [...] reflete uma postura que, aproveitando o aumento dos espaços da jurisdição, investe no reforço da discricionariedade judicial, cujo maior e pio (d)efeito é o enfraquecimento da normatividade da Constituição e, consequentemente, das bases do próprio regime democrático. (TRINDADE; MORAIS, 2011, p. 160)

Conforme Streck, que é claramente contra o ativismo judicial, “o judiciário não pode substituir o legislador (não esqueçamos, aqui, a diferença entre ativismo e judicialização: o primeiro, fragilizador da autonomia do direito, o segundo, ao mesmo tempo, inexorável e contingencial)" (STRECK, 2014, p. 289). A judicialização figura como um mecanismo que, em certa medida, não viola a legitimidade democrática, pois resolve casos pontuais e referente ao caso concreto, enquanto que o ativismo o julgador se torna legislador o que leva à usurpação de competência.

Um dos grandes problemas para a compreensão do direito e das suas peculiaridades, está, sem sombra de dúvidas, na estrutura semântica das locuções, orações que constroem o arcabouço jurídico. A indefinição conceitual, parece ser um dos grandes impasses do direito, 
levando a uso indiscriminado e até pejorativo de expressões. O ativismo judicial na maioria das vezes é criticado e carregado de conotação negativa, uma vez que os juízes, considerados ativistas, são tidos com desvalor para a democracia e a separação de poderes (CAMPOS, 2014, p. 149).

No que tange à legitimidade do ativismo o autor defende uma relação de contingência entre ativismo e legitimidade, pois para ele ativismo não é sinônimo de ilegitimidade, em suas palavras

[...] Não há, segundo a perspectiva conceitual deste trabalho, como afirmar aprioristicamente que uma decisão judicial ativista é legítima ou ilegítima, pois isso dependerá, em cada caso concreto, da conformidade do exercício do poder judicial com os limites institucionais mais ou menos claros impostos pela perspectiva constituição e regência e pelas diferentes variáveis políticas e sociais presentes. Mai do que um problema puramente terminológico, trata-se de compreender que a extensão do papel do juiz pode desempenhar em democracias constitucionais depende de uma variedade de elementos que não permite avaliação de legitimidade abstrata apriorística, nem mesmo do tipo tudo ou nada das decisões ativistas. $\mathrm{O}$ ativismo judicial pode ser bom ou ruim, legítimo ou ilegítimo, e isso é contingente. (CAMPOS, 2014, p. 159)

Desse mote podemos destacar a percepção, quanto a legitimidade ou ilegitimidade do ativismo na corte e os tribunais brasileiros. Trindade e Morais, asseveram que no Brasil a jurisprudência quanto a efetivação dos direitos fundamentais, com o intuito de conceder efetividade as normas programáticas da Constituição, era um tanto quanto tímida. No entanto com o advento da Emenda Constitucional $n^{\circ} 45$, houve uma crescente nas práticas ativistas do judiciário destacando o papel de salvaguardar a concretização dos direitos fundamentais (2011, p. 155-156).

As críticas acerca da atuação expansiva do Poder Judiciário percorre a alocação orçamentária para a implantação ou efetivação das políticas públicas. Para os que contestam o essa postura do judiciário afirmam que a conduta dos julgadores deveria ser justamente ao contrário, isto é, “a autorrestrição judicial ${ }^{6}$ : devem evitar declarar a nulidade de leis e atos administrativos e manter-se distantes dos temas de natureza política, das escolhas políticas que, em uma democracia, cabem aos poderes batizados pelo voto popular" (CAMPOS, 2016, p. 218).

\footnotetext{
6 "Autorrestrição judicial, assim como ativismo judicial possui diferentes significados, no entanto, alguns fundamentos iniciais marcam a sua origem: "deferência em favor dos outros poderes e a prudência como mecanismo de preservação da própria autoridade judicial”. (CAMPOS, 2014, 176-177).
}

Rev. de Argumentação e Hermeneutica Jurídica | e-ISSN: 2526-0103 | Porto Alegre | v. 4 | n. 2 | p. 80 - 101 | Jul/Dez. 2018 
Em contrapartida à autorrestrição judicial tem-se o ativismo judicial, definido pelo autor como

[...] como o exercício expansivo, não necessariamente ilegítimo, de poderes político-normativos por parte de juízes e cortes em face dos demais atores políticos, que: (a) deve ser identificado e avaliado segundo os desenhos institucionais estabelecidos pelas constituições e leis locais; (b) responde aos mais variados fatores institucionais, políticos, sociais e jurídico-culturais presentes em contextos particulares e em momentos históricos distintos; (c) se manifesta por meio de múltiplas dimensões de práticas decisórias. (CAMPOS, 2014, p. 164)

Verifica-se nas demais cortes constitucionais, de diversos países, características que se manifestam por meio de multidimensões ${ }^{7}$, quais sejam, "ativismo judicial e interpretação da Constituição"; "ativismo judicial e criação legislativa"; "ativismo judicial e deferência aos demais poderes"; "ativismo judicial e afirmação de direitos"; "ativismo judicial e políticas públicas e sociais"; "ativismo judicial e autoexpansão da jurisdição e dos poderes decisórios"; "ativismo judicial e superação de precedentes"; "ativismo judicial e maximalismo"; "ativismo judicial e partidarismo" e "ativismo judicial e soberania judicial" (CAMPOS, 2014, p. 165173). Analisar o ativismo por meio dessas dimensões conceituais consiste em delimitar o espaço de discussão entre as diferentes manifestações para compreender e classificar se uma decisão é ativista ou não de acordo com cada critério expresso na dimensão. Para além da dimensão conceitual multidimensional, há ainda a dimensão decisória, na qual vamos nos ater devido a delimitação do nosso objeto de estudo.

No Brasil temos o Supremo Tribunal Federal como a instituição que está na vitrine do ativismo judicial. O Supremo Tribunal Federal apresenta cinco versões diferente de ativismo. Em breve síntese destacamos as dimensões conforme a organização feita por Campos (2014, 356-358):

a) Dimensão metodológica: significa compreender o modo de interpretação e aplicação da normatização constitucional ou legal. O Tribunal não se restringe em apenas aplicar a norma, mas tem uma postura mais ativa, ampliando ou restringido a aplicação da dispositivo, indo além ou contra a interpretação

\footnotetext{
${ }^{7}$ Respeitando os limites estruturais do presente artigo, não é possível explorar de modo acentuado, como merecia, cada uma das dimensões. Para complementar sugere-se a leitura de Dimensões do ativismo judicial do STF, Carlos Alexandre de Azevedo Campos, Editora Forense, 2014.
}

Rev. de Argumentação e Hermeneutica Jurídica | e-ISSN: 2526-0103 | Porto Alegre | v. 4 | n. 2 | p. 80 - 101 | Jul/Dez. 2018 
imediata. O papel do julgador é de uma acentuada criação judicial do direito, um exemplo seria o "caso do nepotismo", "caso da união homoafetiva";

b) Dimensão processual: ocorre quando o Supremo Tribunal Federal amplia a própria participação na construção da ordem jurídica e democrática pela expansão dos instrumentos processuais, por exemplo dessa dimensão temos a inovação do instituto da 'reclamação' ao STF;

c) Dimensão estrutural do ativismo judicial: denota o comportamento do Tribunal frente a decisões de outros poderes e o quanto ele interfere nessas decisões que costumeiramente são de outros poderes, como exemplo pode-se verificar o "caso Batistti”, em relação ao Poder Executivo e em relação ao Poder Legislativo "caso IPMF";

d) Dimensão de direitos do ativismo judicial: se refere a expansão da jurisprudência sob a perspectiva quantitativa e qualitativa dos conceitos normativos como o da dignidade da pessoa humana, da liberdade, entre outros, exigindo do Estado o respeito e a realização de direitos fundamentais. É divido em dimensão negativa - defesa - (Lei da Imprensa; quebra de sigilo bancário) ou positiva - prestacional - (caso Lei Maria da Penha que requer políticas públicas para a melhor eficácia);

e) Dimensão antidialógica: nesse caso o Supremo Tribunal Federal, avoca para si a competência exclusiva de único intérprete da Constituição, sendo o titular da palavra final sobre o que diz o texto constitucional. Essa dimensão é considerada a única aprioristicamente ilegítima do ativismo constitucional;

Com base no que foi exposto percebe-se que o ativismo judicial, em que pese, seja criticado de modo pontual pela doutrina, é um fenômeno que alcança dimensões globalizadas, ou seja, está presente no cotidiano e no fazer decisório das cortes supremas e constitucionais, além dos tribunais e varas judiciais. Trata-se de um tema que não "sai de moda", conforme verifica-se por meio das criativas decisões exaradas pelos tribunais. Como por exemplo decisões em que, no caso brasileiro, Supremo Tribunal Federal adentra em que a solução está na competência do Poder Legislativo.

Nada obstante, tem-se a livre formação de convencimento de um juiz para decidir sobre o caso concreto, uma faculdade democraticamente legitima. O julgador tem o dever de fundamentar suas decisões, sendo observado o que dispõe o artigo 927 do CPC que apresenta 
um rol exemplificativo há a possibilidade de outros instrumentos, podendo, portanto, utilizar as decisões estrangeiras para solucionar um fato exclusivamente nacional, pois um dos quesitos para a legitimidade da sua decisão é a fundamentação, que por óbvio não deve ir de encontro com o texto constitucional, principalmente no que se refere às cláusulas pétreas.

Um fato elementar em toda essa discussão entre Poder Judiciário, Executivo e Legislativo, é que um lugar só pode ser ocupado, quando há espaço para ele, se atualmente o judiciário tem tido uma postura mais ativa e expansiva é porque esse espaço foi permitido pelos demais poderes, pois a população viu no judiciário um meio de efetivar direitos fundamentais básicos. Com isso a internalização das decisões estrangeiras não nos parece um ativismo negativo, mas sim uma maneira de encontrar a solução correta para o caso concreto, além de ser uma maneira de equiparar os direitos fundamentais entre os atores transnacionais.

\section{CONCLUSÃO}

A globalização é um fato do qual não podemos fugir, estamos inseridos em mundo cujos espaços vem diminuindo de maneira vertiginosa, seja por meio da comunicação ou da tecnologia. As fronteiras estão a cada dia mais permeáveis e as experiências podem ser trocadas praticamente no mesmo instante. A globalização permitiu a rapidez das trocas de informações, salienta-se a globalização, pois a ferramenta da tecnologia sem a globalização propriamente dita, ficaria restrita às fronteiras de sua criação.

A evolução (ou as novas perspectivas) do Estado foram desenvolvidas inicialmente, pode-se com isso destacar que as transformações que sofreram os Estados, continuarão a serem paulatinamente inseridas, tendo em vista o alargamento das fronteiras. Por óbvio um Estado não perde sua soberania com a globalização, mas precisa redefinir o seu conceito, pois a sociedade requer essa nova estruturação organizacional do Estado, para que possa dar conta dos novos atores transnacionais que adentram no território.

Parece-nos certo dizer que, embora a globalização traga consigo alguns inconvenientes, ela tem um cunho positivo, já que favorece a circulação de capitais, de serviços, de pessoas, gerando oportunidades antes impensáveis. Este fenômeno não atinge apenas a área econômica, tecnológica, mas também adentra searas, como o caso do Poder Judiciário, que nos leva a reflexões acerca de mecanismos que são severamente criticados nesse órgão.

Rev. de Argumentação e Hermeneutica Jurídica | e-ISSN: 2526-0103 | Porto Alegre | v. 4 | n. 2 | p. 80 - 101 | Jul/Dez. 2018 
O Poder Judiciário é a "bola da vez" no Brasil atualmente, diante da sua exacerbada criatividade decisória, esta instituição está na vitrine diariamente. O que em um país democrático como esse é fundamental a nosso ver. Tomar conhecimento das decisões, entendê-las e criticá-las faz com que haja uma participação mais efetiva do cidadão. Isto é um fato desconhecido no Brasil, qual seja, conhecer a função de cada poder para que se saiba a quem recorrer para a efetivação de seus direitos de forma adequada e sem burocracia.

Embora seja o ideal, não é o que ocorre nesse país, o agigantar do Poder Judiciário se deu na EC n. 45, foi a partir dela que os tribunais se viram como concretizadores dos direitos fundamentais. O cidadão conhecendo seus direitos e não tendo acesso a eles, viu no Poder Judiciário a maneira de alcançá-lo. Desta feita o Poder Judiciário iniciou uma fase ativista. A judicialização para a garantia dos direitos abriu um espaço para que os tribunais interviessem na função dos demais poderes.

Para solucionar um caso concreto os julgadores tem a faculdade de escolher o caminho a seguir que lhe seja mais convincente, e com a globalização a formação do convencimento do juiz expandiu para a internalização de decisões estrangeiras, o que nos parece que não pode ser considerado um ativismo judicial sob a ótica pejorativa, mas sim um meio a mais para uma decisão mais correta que respeite a historicidade da norma, dando uma interpretação mais adequada.

Temas como ativismo judicial, globalização, não se exaurem em poucas páginas, pois carecem de uma profunda pesquisa teórica, no entanto, de maneira provisória podemos sublinhar que é necessário que todos os poderes do Estado cumpram com as suas funções de modo que não abram espaço para a intervenção de outro poder, e assim se concretizará o disposto na Constituição Federal que destaca a independência e a harmonia entre os poderes do Estado. O caminho é árduo, longo e difícil, mas não impossível!

\section{REFERÊNCIAS BIBLIOGRÁFICAS}

ARGUELHES, Diego Werneck. Soberania. In. BARRETO, Vicente de Paulo (Coord.) Dicionário de Filosofia do Direito. São Leopoldo: Editora Unisinos, 2009.

ARNAUD, André-Jean. Governar sem fronteiras: entre globalização e pós-globalização. Rio de Janeiro: Lumen Juris, 2007. 
ATZ, Ana Paula; SUBTIL, Leonardo Camargo. Soberania. In. BARRETO, Vicente de Paulo (Coord.) Dicionário de Filosofia Política. São Leopoldo: Editora Unisinos, 2010.

AZAMBUJA, Darcy. Teoria Geral do Estado. ed. 23. Rio de Janeiro: Globo, 1984.

BARBOSA, Anna Christina Freire. Democracia transnacional : Notas acerca da (in)viabilidade de um projeto pós-nacional. Revista Cronos, [S.1.], v. 12, n. 1, abr. 2013. ISSN 1982-5560. Disponível em: <https://periodicos.ufrn.br/cronos/article/view/2204>. Acesso em: 29 jul. 2018.

BARROSO, Luís Roberto. Prefácio. In: CAMPOS, Carlos Alexandre de Azevedo. Dimensões do ativismo judicial do STF. Rio de Janeiro: Forense, 2014.

BAUMAN. Zigmunt. Globalização: As consequências humanas. Rio de Janeiro: Jorge Zahar Editor, 1999 PDF

CAMPOS, Carlos Alexandre de Azevedo. Dimensões do ativismo judicial do STF. Rio de Janeiro: Forense, 2014.

CANDEAS, Ana Paula Lucena Silva. Juízes para o mercado? Revista do Tribunal Regional do Trabalho da $\mathbf{1 5}^{\mathbf{a}}$ Região: N. 33, jul./dez. 2008. Disponível em: <https://juslaboris.tst.jus.br/handle/20.500.12178/105126>. Acesso em: 29 jul. 2018.

HABERMAS, Jürgen. A constelação pós-nacional: ensaios políticos. São Paulo: Litera Mundi, 2001.

HART, Herbert L. A. O conceito de direito. 6. ed. Lisboa: Fundação Calouste Gulbenkian, 2011.

LEAL, Mônia Clarissa Hennig. Estado de Direito. In: BARRETO, Vicente de Paulo (Coord.). Dicionário de Filosofia do Direito. São Leopoldo: Editora Unisinos, 2009.

NUNES JÚNIOR, Flávio Martins. Curso de direito constitucional. 1. ed. São Paulo: Editora Revista dos Tribunais, 2017.

MAQUIAVEL. O príncipe. São Paulo: Círculo do Livro S.A., 1980?

MORAIS, José Luis Bolzan de. Estado. In. BARRETO, Vicente de Paulo (Coord.) Dicionário de Filosofia Política. São Leopoldo: Editora Unisinos, 2010.

. Estado de direito. In. BARRETO, Vicente de Paulo (Coord.) Dicionário de Filosofia Política. São Leopoldo: Editora Unisinos, 2010

PINHEIRO FILHO, José Muiños; CHUT, Marcos André. Estado. In: BARRETO, Vicente de Paulo (Coord.). Dicionário de Filosofia do Direito. São Leopoldo: Editora Unisinos, 2009. 
SERRAGLIO, Priscila Zilli. A Globalização do Direito e a Mundialização dos Juízes. In: PAFFARINI, Jacopo; ROSENFIELD, Luis; STAFFEN, Márcio Ricardo. (Orgs). Transnacionalismo, globalização e direitos humanos. Itajaí: UNIVALI, 2015. Disponível em: 〈http://www.univali.br/ppcj/ebook>. Acesso em: 30 jul. 2018.

STAFFEN, Márcio Ricardo. Interfaces do Direito Global. 2. ed. Rio de Janeiro: Lumen Juris, 2018.

STAFFEN, Márcio Ricardo. A tutela jurídica global da alimentação. In: TRINDADE, André Karan; ESPÍNDOLA, Angela Araújo da Silveira; Boff, Salete Oro (Orgs). Direito, democracia e sustentabilidade: anuário do programa de Pós-graduação Stricto Sensu em Direito da Faculdade Meridional. Passo Fundo: Editora IMED, 2015.

STRECK, Lenio Luiz. Jurisdição constitucional e decisão jurídica. 4. ed. São Paulo: Editora Revista dos Tribunais, 2014.

TONET, Fernando. Reconfigurações do constitucionalismo: evolução e modelos constitucionais sistêmicos na pós-modernidade, 2013.

TRINDADE, André Karam; MORAIS, Fausto Santos de. Ativismo judicial: as experiências norte-americana, alemã e brasileira. Revista da Faculdade de Direito - UFPR, Curitiba, n. 53, 2011. Disponível em: <https://revistas.ufpr.br/direito/article/view/30764>. Acesso em: 27 jul. 2018.

WENTZ, Gustavo; STAFFEN, Márcio Ricardo. Os juízes e os tribunais como agentes da globalização. A utilização de leis e jurisprudência estrangeiras pelo Supremo Tribunal Federal no ano de 2015. In: PIRES, Cecília Maria Pinto; PAFFARINI, Jacopo; CELLA, José Renato Gaziero (Orgs). Direito, Democracia e Sustentabilidade: programa de pós-graduação stricto sensu em Direito da Faculdade Meridional. Erechim: Deviant, 2017.

ZOLET, Lucas Augusto da Silva; MORAIS, Fausto Santos. Espaços contemporâneos de expansão da autoridade privada: um estudo sobre globalização e transnacionalismo. RVMD, Brasília, V. 10, $\mathrm{n}^{\mathrm{o}}$ 1, p. 446-470, Jan-jun., 2016. Disponível em: <https://portalrevistas.ucb.br/index.php/rvmd/article/view/6776/4720>. Acesso em: 30 jul. 2018. 